\title{
Algılanan Yönetici Mizahının Üretkenlik Karşıtı İş Davranışları Üzerindeki Etkisi ${ }^{1}$
}

\author{
Burak ÖZDEMIR ${ }^{2}$ ve Melih IPPEK ${ }^{3}$
}

Öz

$\mathrm{Bu}$ araşıırmada, algılanan yönetici mizahının üretkenlik karşıtı iş davranışları (ÜKID) üzerindeki etkisinin Genişletme ve İnşa Etme Teorisi (GIET) kapsamında incelenmesi amaçlanmaktadır. Bu amaca uygun olarak ağaç, ağaç ürünleri ve mantar ürünleri imalatı sektöründe faaliyet gösteren üç firmanın 228 çalışanından veriler kolayda örnekleme yöntemiyle elde edilmiştir. Araştırma bulguları alaycı mizahın bireylerarası sapma davranışı ve örgüte yönelik sapma davranışını pozitif yönde etkilediğini göstermektedir. Ayrıca reddedici mizahın bireylerarası sapma davranışını negatif yönde, üretici-sosyal mizahın ise örgüte yönelik sapma davranışını pozitif yönde etkilediği belirlenmiştir. Bu doğrultuda bulgular Genişletme ve İnşa Etme Teorisi çerçevesinde tartışılmış ve kültürel bağlamın sonuçlar üzerinde etkili olduğu sonucuna varılmıştır.

Anahtar Kelimeler: Genişletme ve İnşa Etme Teorisi, Algılanan Yönetici Mizahı, Üretkenlik Karşıtı İş Davranışları

\section{The Effect of Perceived Supervisor Humor on Counterproductive Work Behaviors}

\begin{abstract}
In this research, it is aimed to examine the effect of perceived supervisor humor on counterproductive work behaviors within the scope of the Broaden and Build Theory. In accordance with this purpose, data was obtained by convenience sampling method from 228 employees of three firms operating in the manufacture of wood and of products of wood and cork sector. Research findings show that cynical humor positively affects interpersonal and organizational deviance behaviors. In addition, it was determined that rejectionist humor affects interpersonal deviance behaviors negatively, and producer humor positively affects organizational deviance behaviors. Accordingly, the findings were reviewed inside the framework of Broaden and Build Theory and it was concluded that cultural context had an impact on the results.
\end{abstract}

Key Words: Broaden-and-Build Theory, Perceived Supervisor Humor, Counterproductive Work Behaviors

Atıf İçin / Please Cite As:

Özdemir, B. ve İpek, M. (2021). Algılanan yönetici mizahının üretkenlik karşıtı iş davranışları üzerindeki etkisi. Manas Sosyal Araștirmalar Dergisi, 10(4), 2289-2300.

Geliş Tarihi / Received Date: 31.03.2021

Kabul Tarihi / Accepted Date: 03.06.2021

\footnotetext{
${ }^{1}$ Bu makale Dr. Öğr. Üyesi Burak ÖZDEMİR danışmanlığında Kastamonu Üniversitesi Sosyal Bilimler Enstitüsü yüksek lisans öğrencisi Melih IPEK'in yüksek lisans tezinden üretilmiştir.

2 Dr. Öğr. Üyesi - Kastamonu Üniversitesi İktisadi ve İdari Bilimler Fakültesi, bozdemir@kastamonu.edu.tr

ORCID: 0000-0002-2710-4112

3 Yüksek Lisans Öğrencisi - Kastamonu Üniversitesi Sosyal Bilimler Enstitüsü, melih.ipek@yahoo.com

(D) ORCID: 0000-0002-4471-7498
} 


\section{Giriş}

Mizah, yöneticilerin işyerinde diğerleriyle ilişki kurmak için kullanabileceği etkili bir iletişim stratejisidir (Campbell, Martin ve Wanzer, 2001, s. 68). Mizah, bireylerin hem fizyolojisi hem de psikolojisi üzerinde olumlu etkiler bırakmaktadır (Astedt-Kurki ve Isola, 2001, s. 30). Örgütlerde başar1 ve performansın artması için pozitif mizahın aktif olarak kullanılması önem arz etmektedir (Çakmak ve Baş, 2016, s. 122). Mizahın olumlu yönde kullanılması örgüt içerisindeki pozitif davranışları geliştirirken (Decker ve Rotondo, 1999; Büyükyllmaz, 2018), olumsuz yönde kullanımı negatif çıtıllarla (Avtgis ve Taber, 2006; Dinç ve Cemaloğlu, 2018) ilişkilendirilmektedir.

Genişletme ve İnşa Etme Teorisi (GİET) çerçevesinde pozitif yönetici mizahının çalışanlarda pozitif duyguların oluşumunda etkili olduğu belirtilmektedir (Wijewardena, Hartel ve Samaratunge, 2017, s. 1316; Cooper, Kong ve Crossley, 2018, S. 769). GIET, pozitif duyguların bireylerin düşünce-eylem repertuarlarını genişlettiğgini, kalıcı olumsuz duyguları ortadan kaldırdığını, psikolojik dayanaklılı̆̆ güçlendirdiğini, kişisel kaynakların oluşumunu desteklediğini ve psikolojik ve fiziksel iyi oluşu arttırdığını öne sürmektedir (Fredrickson, 2004, s. 1375). Teoriye göre zaman içerisinde pozitif duyguların tetiklemesiyle genişleme gerçekleşmekte, fiziksel kaynaklar (örneğin, fiziksel beceriler, sağlık, uzun ömür), sosyal kaynaklar (örneğin, arkadaşlıklar, sosyal destek ağları), entelektüel kaynaklar (örneğin, uzman bilgisi, entelektüel karmaşıllık) ve psikolojik kaynaklar (örneğin, dayanıklılık, iyimserlik, yaratıcılık) inşa edilmektedir (Fredrickson, Tugade, Waugh ve Larkin, 2003, s. 367). Fredrickson (2000, s. 131) örgütsel bağlamda pozitif duyguların neden önemli olduğunu değerlendirmiş ve bireylerdeki pozitif duyguların örgütlerin gelişimine ve başarılı olmasına yardımcı olarak örgütsel işleyişe katkı sağladığını belirtmiştir. Yine, GIET çerçevesinde örgütler üzerine gerçekleştirilen araştırmaları yorumlayan Fredrickson (2013, s.34-35) pozitif duyguların kişilerin üretkenliğini, iş performansını, fiziksel ve ruhsal sağlığını arttırdığını öne sürmüştür. Dolayısıyla pozitif yönetici mizahının yaratacağı pozitif duygular ile çalışanların üretkenlik karşıtı iş davranışlarının (ÜKİD) kısıtlanacağı öngörülmektedir.

Spanouli ve Hofmans (2020, s. 20) GİET’ten hareketle pozitif duyguların düşünce yapısını genişleteceğini, çalışanlarda kaynaklar oluşumuna yardımcı olacağını ve bu kaynaklar üzerinden ÜKi̇D’in incelenebileceğini belirtmiştir. Bunun yanı sıra GİET’te olumsuz duygular söz konusu olduğunda zihinsel aktivitenin kısıtlandığ1 vurgulanmaktadır (Fredrickson, 2004, s. 1370). Olumsuz duygular, aşırı, uzun süreli veya bağlamsal olduğunda fobiler ve anksiyete bozuklukları, saldırganlık ve şiddet, depresyon ve intihar, yeme bozuklukları ve cinsel işlev bozukluğundan stresle ilişkili bir dizi fiziksel bozukluğa kadar kişinin hayatında ve içinde bulunduğu toplulukta ciddi sorunlar yaratmaktadır (Fredrickson, 2004, s. 1367). GİET kapsamında örgütler üzerine gerçekleştirilen araştırmalarda bu olumsuz duyguların ÜKİD’in bir öncüsü olduğu düşünülmektedir (Kiffin-Petersen, 2015; Diener, Thapa ve Tay, 2020). Yönetici mizahının pozitif yönü olduğu gibi negatif yönü de bulunmaktadır (Evans ve Steptoe-Warren, 2018, s. 443). Negatif yönetici mizahının çalışanlarda olumsuz duygular yaratarak ÜKİD’e sebebiyet vereceği öngörülmektedir. Çünkü olumsuz duygular, bireye ve örgütüne büyük zararlar verebilmektedir (Fredrickson, 1998, s. 301).

Mizah ile ÜKID arasındaki ilişki yazında daha önce çeşitli yönleriyle incelenmiştir. He ve Li (2019) saldırgan lider mizahının genel işyerinde sapkınlık davranışı üzerindeki etkisine bakmıştır. Yam, Christian, Wei, Liao ve Nai (2018) saldırgan lider mizahı ve espri odaklı lider mizahının sapma davranışıla arasındaki ilişkiye odaklanmıştır. Comeau (2016) ise iş ortamında kullanılan mizah türlerinin (bireyin iş arkadaşlarının mizah kullanımı ve kendisinin mizah kullanımı) ÜKİ'e yönelik etkisini ele almıştır. Ancak algılanan yönetici mizahı bağlamında özellikle de yönetici mizahının alt boyutları üzerinden ÜKİD boyutlarına yönelik etkinin incelenen yazın kapsamında çalışılmadığı görülmektedir. Ayrıca ikili arasındaki ilişki daha önce GIETT kapsamında değerlendirilmemiştir. Buradan hareketle yazındaki boşluk dikkate alınarak araştırmada algilanan yönetici mizahının ÜKID üzerindeki etkisi GİET çerçevesinde incelenmektedir.

\section{Algılanan Yönetici Mizahı}

İşyerinde mizah, bir çalş̧anın örgütteki diğer kişiyi ve ya kişileri güldürmek amacıyla paylaşmış olduğu herhangi bir olay olarak tanımlanmaktadır (Cooper, 2005, s.766-767). Örgüt içerisinde astların ve üstlerin mizah kullanımlarıyla birbirlerini etkiledikleri görülmektedir (Decker ve Rotondo, 1999, s. 961). Mizah, örgüt içerisinde kişilerin birbirleriyle kaynaşmasına, örgüt kültürünü benimsemesine, çalışanların olaylara ve durumlara olumlu bakabilmesine, örgüt kültürünün ve istenilen davranışların gelişmesine yardımc1 olmaktadır (Barut ve Onay, 2017, s. 423). 
Yönetici pozisyonlarındaki bireyler çalışma yaşamları boyunca stresli olaylarla karşılaşmaktadır. Stresi yönetebilen kişiler yaşam kalitelerini kendileri ve çalışanları için daha iyi bir hale getirmektedir. Gelişmiş mizah becerisine sahip yöneticiler, problemlere farklı bir bakış açısıyla, çalışanlara da neşeli bir şekilde yaklaşarak onlanı motive edebilmektedir (Alan ve Şen, 2015, s. 155). Mizahın yapıcı etkilerinin yanı sıra yıkıcı etkileri de göz ardı edilmemelidir. Yöneticilerin mizahı doğru kullanmaları gerektiği unutulmamalıdır. Aksi takdirde mizah yıkıcı olmakta iletişimi azaltarak örgüt içerisinde yıkıcı çatışmalara sebebiyet verebilmektedir (Şahin, 2016, s. 2-3). Eğlencenin ve mizahın toplumlar ve kültürler arasında hatta aynı kültürlerin içerisinde bile değişkenlik göstermesinden dolayı mizahın doğru bir şekilde kullanılması önemlidir (Bilginoğlu ve Yozgat, 2018, s. 401).

Yönetici mizahı, iki pozitif yönde, iki negatif yönde olmak üzere dört boyut kapsamında değerlendirilebilir. Bu çerçevede onaylayıcı, saldırgan, kendini yıkıcı ve üretici mizah olmak üzere dört farklı mizah boyutu bulunmaktadır (Martin, Doris, Larsen, Gray ve Weir, 2003, s. 53). Onaylayıcı mizah ve kendini geliştirmeye yönelik mizah eğlenme ile olumlu bir ilişki içerisindeyken; alaycı mizah ve kendini yıkıcı mizah eğlenmeyle olumsuz ilişski içerisindedir (Liu, 2012, s. 22). Cemaloğlu, Recepoğlu, Şahin, Daşç1 ve Köktürk (2012) araştırmasında Babad'ın (1974) çalışmasında hareketle yönetici mizahını onaylayıcı mizah, üretici-sosyal mizah, alaycı mizah, reddedici mizah ve mizahi olmayan tarz olarak sınıflandırmıştır. Onaylayıcı mizah, eğlence yaratmak, kişilerarası gerginliği azaltmak ve ilişkileri kolaylaştırmak için şaka yapma ya da kendiliğinden şaka yapan kişi olma eğilimini ifade etmektedir (Liu, 2012, s. 22). Yöneticiler üretici-sosyal mizah tarzını stresli ve negatif durumlarda ortamı yumuşatmak ve kendilerini sakinleştirmek için kullanmaktadır (Çetin ve Altun, 2018, s. 93). Alaycı mizah nevrotiklik ve düşmanlık, öfke ve saldırganlık ile pozitif korelasyon içerisindedir. Alaycı mizah, başkalarıyla alay etmek, olumsuz eleştiri yapmak veya kişileri manipüle etmek için kullanılmaktadır (Martin vd. 2003, s. 54). Reddedici mizah tarzını benimseyen kişilere göre mizah yapan kişiler güvenilir değildir. Bu mizah tarzını benimseyen yöneticiler, mizah yapan bireyleri mesleğin ciddiyetini ve değerlerini kavrayamamış bireyler olarak görmektedir. Algilanan yönetici mizahının son boyutu mizahi olmayan mizah tarzıdır. Mizahi olmayan tarza sahip yöneticiler reddedici mizahtan farklı olarak nadiren espri ve şaka yaparlar ve mizahı etkili olarak kullanmazlar (Dinç ve Cemaloğlu, 2018, s. 4).

\section{Üretkenlik Karşıtı İş Davranışları}

Sackett (2002, s. 5) ÜKID’i örgütün amaçlarıyla meşru çıkarlarını olumsuz bir şekilde etkileyen ve kasıtlı olarak yapılan zararlı davranışlar şeklinde tanımlamaktadır. Burada, davranışın sonuçlarından ziyade davranışın kendisi önem arz etmektedir. ÜKID'de kasıtlı olarak yapılan olumsuz davranışlara yoğunlaşılmaktadır. İstenilmeden yapılan davranışlar kişilere veya örgütlere büyük zararlar verse bile bunlar ÜKID değildir (Gruys ve Sackett, 2003, s. 30). ÜKID, sapkın ve anti sosyal davranış olarak da nitelendirilebilmektedir (Lau, Au ve Ho, 2003, s. 73). Hırsızlık, sabotaj, sözlü sataşma, çabayı durdurma, yalan söyleme, iş birliğini reddetme ve fiziksel saldırı gibi eylemler bu kapsamda değerlendirilmektedir (Marcus ve Schuler, 2004, s. 652; Penney ve Spector, 2005, s. 777).

ÜKID’in, bireysel ve örgütsel düzeyde sonuçları bulunmaktadır. Bu doğrultuda iki farklı ÜKİD boyutu olduğu belirtilmektedir. Bunlar bireylerarası sapma ve örgüte yönelik sapma davranışlarıdır (Berry vd., 2007; Robinson ve Bennett, 1995). Bireylerarası sapma davranışları politik sapma ve kişisel sapmayı kapsamakta, örgüte yönelik sapma davranışları ise üretim sapması ve mülkiyet sapması davranışını içermektedir (Robinson ve Bennett, 1995, s. 565-566). Sapma davranış1 örgüte yönelik olduğunda örgüte yönelik sapma, örgütün üyelerine yönelik olduğunda kişilerarası sapma söz konusu olmaktadır (Bennett ve Robinson, 2000, s. 350). Bireylerarası sapma davranışlarından politik sapma, diğerlerine göre daha az önemi olan ve kişilere zarar vermeyi amaçlayan bir davranışlardır. Agresif davranışların sonucunda ortaya çıkan kişisel saldırı ise diğer kişilere düşmanca bir şekilde davranma şeklidir. Örgüte yönelik sapma davranışlarından üretim sapması kaynaklar israf edilerek üretimi geciktirecek eylemler sergilemek, çalışma saatlerinde çalışmamak, işten erken ayrılmak, uzun süreli ve gereksiz molalar vermek, kasıtlı olarak yavaş çalışmak, kaynak ve zamanları israf etmek, masrafları olduğundan fazla göstermek gibi davranışları kapsamaktadır. Mülkiyet sapmasında ise ekipmanlara zarar vermek, hırsızlık yapmak, yalan konuşmak ve rüşvet almak gibi davranışlar bulunmaktadır (Robinson ve Bennett, 1995, s. 563-565).

\section{Algılanan Yönetici Mizahı ile Üretkenlik Karşıtı İş Davranışları Arasındaki İlişki}

Yönetim uygulamasında mizah kullanımı dikkat çekmeye başlayan bir olgudur. Yöneticilerin olumlu mizahı etkin bir şekilde kullanması durumunda örgüt üyelerinin iş tatminleri yüksek olmaktadır (Decker, 
1987, s. 225). Mizah, insan etkileşiminin ortak bir unsurudur ve bu nedenle çalışma grupları ve örgütsel bağlam üzerinde büyük bir etkiye sahiptir. Yöneticiler, stresi azaltmak ve liderliği, grup tutarlllı̆̆ın, iletişimi, yaratıcılı̆̆ı ve organizasyon kültürünü arttırmak için mizahı aktif olarak kullanmaktadır. İstenen örgütsel sonuçlara ulaşmak amaciyla uygun mizah stilini seçilmesi ile pozitif örgütsel sonuçlar elde edilmesi mümkündür (Romero ve Cruthirds, 2006, s. 58).

Yöneticilerin, çalışanlarıyla ilişkilerinde mizahı alay etmek, takılmak, aşağılamak, dalga geçmek veya iğnelemek amacıyla kullanması çalışan davranışlarında olumsuzluklara sebebiyet vermektedir (Büyükyılmaz, 2018, s. 143-144). Bu bağlamda yöneticilerin mizahı kullanırken dikkatli olması gerekmektedir. Aksi takdirde adaletsizlik hisseden ve eşitsizliğe maruz kaldığını algılayan çalışanlar örgüte ve diğer çalışanlara karşı öç alma duygusu ile istenilmeyen davranışlar sergileyebilmektedir (Nayir, 2016, s. 13).

He ve Li (2019) 174 çalışan ve yöneticinin oluşturduğu örneklem üzerinde gerçekleştirdikleri çalışmalarında saldırgan lider mizahının çalışanların ÜKİD üzerinde güçlü ve pozitif yönde bir etkide bulunduğunu tespit etmişlerdir. Yam ve diğerleri (2018) farklı sektörlerden 215 katılımc1 ile gerçekleştirdikleri çalışmada lider mizahını saldırgan ve espri odaklı olarak iki boyutta incelemişlerdir. Saldırgan mizahın sapma davranışılla arasında bir ilişki olmadığı, espri odaklı mizahın ise sapma davranışıyla pozitif yönde ilişki içerisinde olduğu görülmüştür. Comeau (2016) çalışmasında örgüt ortamında mizah kullanımının ÜKID üzerindeki etkisini değerlendirmiştir. Bu doğrultuda onaylayıc1 mizahın bireylerarası sapma ve örgütsel sapma davranışını negatif, saldırgan mizahın ise bireylerarası sapma davranışını ve örgütsel sapma davranışını pozitif olarak etkilediğini bulgulamıştır. Bununla beraber kendini yıkıcı ve üretici mizahın sapma davranışları üzerinde etkisi bulunamamıştır. Bu bilgiler doğrultusunda araştırma hipotezleri aşağıldaki gibi belirlenmiştir:

- H1: Üretici-sosyal mizah tarzı ÜKID boyutlarını (bireylerarası sapma ve örgütsel sapma) negatif yönde etkilemektedir.

- H2: Onaylayıcı mizah tarzı ÜKID boyutlarını (bireylerarası sapma ve örgütsel sapma) negatif yönde etkilemektedir.

- H3: Alaycı mizah tarzı, ÜKİD boyutlarını (bireylerarası sapma ve örgütsel sapma) pozitif yönde etkilemektedir.

- H4: Reddedici mizah tarzı ÜKİD boyutlarını (bireylerarası sapma ve örgütsel sapma) pozitif yönde etkilemektedir.

- H5: Mizahi olmayan tarz ÜKİD boyutlarını (bireylerarası sapma ve örgütsel sapma) pozitif yönde etkilemektedir.

\section{Yöntem}

Nicel araştırma deseninde tasarlanan bu araştırmada algılanan yönetici mizahı boyutlarının ÜKİD boyutları üzerindeki etkileri incelenmiştir.

\section{Evren - Örneklem}

Araştırma Kastamonu'da “ağaç, ağaç ürünleri ve mantar ürünleri imalatı (mobilya hariç); saz, saman ve benzeri malzemelerden örülerek yapılan eşyaların imalatı" sektöründe faaliyet gösteren 3 firmanın çalışanları ile yürütülmüştür. Bu doğrultuda veriler 228 çalş̧andan kolayda örneklem yöntemiyle elde edilmiştir. Bryman ve Cramer (2005, s. 327) bir araştırmada faktör analizinin başarıyla uygulanabilmesi için örneklem büyüklügünün bir ölçekteki madde sayısının beş katından daha çok olması gerektiğini belirtmektedir. Araştırmada yer alan ölçeklerin toplam madde sayıs 45 olarak belirlenmiştir.

Çalışmaya katılan kişilerin \%70,9’u (161) erkek ve \%58,3’ü (133) evlidir. Eğitim durumları incelendiğinde \%8,3'ünün (19) ilköğretim, \%50'sinin (114) lise, \%28,5'inin (65) ön lisans ve \%13,2'sinin (30) lisans mezunu olduğu görülmüştür. Katılımcıların yaşları en çok 31-40 yaş arası \%46,9 (107) olarak tespit edilmiştir. Son olarak katılımcıların \%8,3’ü (19) alt düzey yönetici, \%15,8’i (36) orta düzey yönetici, $\% 10,5 ’$ i (24) üst düzey yönetici ve \%65,4'ü (149) yönetici olmayan personeldir.

\section{Veri Toplama Araçları}

Araştırmada kullanılan soru kâğıdı üç bölümden oluşmaktadır. İlk bölümde katılımcılara ilişkin bilgi formu bulunmaktadır. İkinci bölüm Algılanan Yönetici Mizahı Ölçeği ve üçüncü bölüm Örgütsel Sapma Ölçeğini içermektedir. 


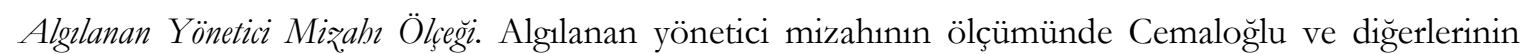
(2012) geliştirdikleri ölçek kullanılmıştır. Ölçek 5 boyuttan oluşmaktadır. Bunlar alaycı mizah tarzı, üreticisosyal mizah, onaylayıcı mizah tarzı, reddedici mizah tarzı ve mizahi olmayan tarzdır. Ölçek 5'li Likert tipindedir ve 30 ifadeden oluşmaktadır. Ölçekteki bazı ifadeler "mizah tarzıyla bizi üzer", "mizahı takdir eder" ve "başkalarıyla şakalaşmaz" şeklindedir. Çalışmalarında ölçeğin yüksek derecede güvenilir $(\alpha=, 92)$ olduğu bulgulanmıştır.

Örgütsel Sapma Ölçeği. ÜKID’in ölçümünde Örgütsel Sapma Ölçeği kullanılmıştır. Örgütsel sapma ölçeğini Bennett ve Robinson (2000) geliştirmiştir. İyigün ve Çetin (2012) çalışmasında Türkçe literatürde yer alan diğer çevirilerden de hareketle ölçeği yeniden tasarlamış ve ön uygulama sonucunda ölçeğin son formunun 15 ifadeden oluştuğunu belirtmiştir. Ölçek iki boyuttan oluşmaktadır. Bu boyutlar bireylerarası sapma ve örgüte yönelik sapmadır. Ölçekte 5'li zaman ölçeği kullanılmaktadır. Ölçekteki bazı ifadeler "işs arkadaşlarım iş yerine geç gelir" ve "iş arkadaşlarım iş yerini erken terk eder" şeklindedir. Çalışmalarında ölçeğin güvenirliği ,89 olarak tespit edilmiştir.

\section{Ön Analizler}

Araştırmada ilk olarak eksik verilerin varllğı frekans analizi ile kontrol edilmiştir. Tespit edilen eksik veri düzeyinin $\% 5$ 'in altında olduğu belirlenmiş (Tabachnick ve Fidell, 2013) ve eksik veriler ortalama değer ile tamamlanmıştır. Araştırmada yer alan değişkenlere ait betimleyici istatistikler ile korelasyonların katsayılarn Tablo 1'de yer almaktadır.

Tablo 1. Betimleyici Istatistikler ile Korelasyon Katsaynlar

\begin{tabular}{|c|c|c|c|c|c|c|c|c|c|c|}
\hline & $A O$ & $S S$ & 1 & 2 & 3 & 4 & 5 & 6 & Çar. & Bas. \\
\hline (1) Bireyleraras1 Sapma & 1,56 & 62 & 1 & & & & & & 1,75 & 5,52 \\
\hline (2) Örgüte Yönelik Sapma & 1,59 & 57 &, $69^{*}$ & 1 & & & & & 1,26 & 1,88 \\
\hline (3) Alaycı Mizah & 1,94 & 99 & $25^{*}$ & $27^{*}$ & 1 & & & & 1,07 & 61 \\
\hline (4) Üretici-Sosyal Mizah & 2,39 & 96 &, $18^{*}$ &, $21^{*}$ &, $41^{*}$ & 1 & & & 26 &,- 51 \\
\hline (5) Reddedici Mizah & 2,07 & ,92 & 02 & ,08 &, $62^{*}$ &, $39^{*}$ & 1 & & 80 & ,26 \\
\hline (6) Onaylayıcı Mizah & 2,91 & 1,04 &, 08 & ,09 &, $17^{*}$ & $68^{*}$ &, $21^{*}$ & 1 &,- 22 &,- 52 \\
\hline (7) Mizahi Olmayan Tarz & 2,27 & 1,02 &, 06 &,- 01 &, $31^{*}$ &, 10 &, $55^{*}$ & 06 & -60 &,- 29 \\
\hline
\end{tabular}

Tablo 1 incelendiğinde çalışanların yöneticilerinde en çok onaylayıcı mizah tarzını gördükleri anlaşılmaktadır. Ayrıca çalışanların işyerinde bireylerarası sapma ve örgüte yönelik sapma davranışı düzeylerine yönelik algısı birbirine oldukça yakın düzeydedir. Araştırmada yer alan değişkenlerin çarpıklık ve basıklık katsayıları incelendiğinde normal dağılım için gerekli niteliğe (In'nami ve Koizumi 2013, s. 34) sahip olduğu görülmektedir. Son olarak araştırmada yer alan bağımsız değişkenlerin (onaylayıcı mizah, alaycı mizah, üretken mizah, reddedici mizah ve mizahi olmayan tarz) arasındaki korelasyon katsayılarının ,70'in altında olması çoklu bağlantı probleminin bulunmadığına (Tabachnick ve Fidell, 2013, s. 90) ve ıraksak geçerliğe (Brown, 2006) bir dayanak oluşturmaktadır.

\section{Geçerlik ve Güvenirlik Analizleri}

Araştırmada ölçeklerin geçerliği Keşfedici Faktör Analizi (KFA) aracillğında incelenmiş güvenirliği ise Cronbach Alfa katsayısından yararlanılarak kontrol edilmişstir. Tablo 2'de Algılanan Yönetici Mizahı Ölçeğinin KFA'ya ilişkin bulguları sunulmuştur. 
ÖZDEMIR ve İPEK

Algılanan Yönetici Mizahının Üretkenlik Karşıtı İş Davranışları Üzerindeki Etkisi

Tablo 2. Algzlanan Yönetici Mizahı Ölçeğine İlişkin KFA Sonuclarn ve Cronbach Alfa Değerleri

\begin{tabular}{|c|c|c|c|c|}
\hline Faktörler & Madde & Fak. Yük. Aralı̆̆ı & $\begin{array}{c}\text { Açıklanan Varyans } \\
(\%)\end{array}$ & 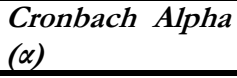 \\
\hline \multirow{11}{*}{ Alayc1 Mizah } & & & 71,011 & ,931 \\
\hline & SM4 & ,862 & \multirow{9}{*}{22,599} & \multirow{10}{*}{,948 } \\
\hline & SM6 & ,861 & & \\
\hline & SM3 & 839 & & \\
\hline & SM8 & 821 & & \\
\hline & SM7 & 820 & & \\
\hline & SM2 & 815 & & \\
\hline & SM5 & ,795 & & \\
\hline & SM1 & ,721 & & \\
\hline & OM2 & 863 & & \\
\hline & OM1 & 847 & \multirow{7}{*}{17,917} & \\
\hline \multirow[t]{6}{*}{ Onaylayıcı Mizah } & OM4 & ,819 & & \multirow[t]{6}{*}{,902 } \\
\hline & OM3 & ,779 & & \\
\hline & OM5 & ,742 & & \\
\hline & UM4 & ,786 & & \\
\hline & UM7 & ,766 & & \\
\hline & UM1 &, 583 & & \\
\hline \multirow[t]{6}{*}{ Üretici-sosyal Mizah } & UM9 & ,543 & \multirow[t]{6}{*}{11,231} & \multirow[t]{6}{*}{,894 } \\
\hline & UM5 & ,530 & & \\
\hline & UM2 &, 509 & & \\
\hline & UM3 & ,503 & & \\
\hline & RM3 & ,734 & & \\
\hline & RM1 & ,710 & & \\
\hline \multirow[t]{4}{*}{ Reddedici Mizah } & RM5 & 654 & \multirow[t]{4}{*}{10,351} & \multirow[t]{4}{*}{,853 } \\
\hline & RM4 & 629 & & \\
\hline & RM2 & 603 & & \\
\hline & MOT2 & ,845 & & \\
\hline \multirow[t]{3}{*}{ Mizahi Olmayan Tarz } & MOT3 & 843, & \multirow[t]{3}{*}{8,912} & \multirow[t]{3}{*}{,840 } \\
\hline & MOT1 & ,777 & & \\
\hline & 907; Barlet & 35,$984 ; d f=378 ; p=.0$ & & \\
\hline
\end{tabular}

*Maddeler arası korelasyon değerleri ,37-,74 arasındadır.

Alg1lanan yönetici mizahı ölçeğinin KMO örneklem yeterliği katsayısı ,907 ve Barlett Küresellik Testi $(\mathrm{p}<.001)$ anlamlıdır. Bu doğrultuda örneklem büyüklüğünün faktör analizi için yeterli ve ölçme aracının faktör çıkarmaya uygun olduğu anlaş1lmaktadır. Tablo 2'de UM6 ve UM8 maddeleri yer almamaktadır. UM6 ve UM8 maddeleri diğer faktöre yüklenmesi nedeniyle analizden çıkartılmıştır. İlgili maddeler analizden çıkartıldığında açıklanan varyans \%70,578'den \%71,011'e yükselmiştir. Ölçek yazınla uyumlu şekilde beş faktörlü yapıdan oluşmaktadır. Ölçeğin ve alt faktörlerinin güvenirliği Cronbach Alfa Katsayısı üzerinden değerlendirildiğinde güvenirlik oldukça yüksektir (Churchill ve Peter, 1984).

Tablo 3. Örgütsel Sapma Ölçeğine İliskin KFA Sonuclarn ve Cronbach Alfa Değerleri

\begin{tabular}{|c|c|c|c|c|}
\hline Faktörler & Madde & Fak. Yük. Araliğı & $\begin{array}{c}\text { Açılanan Varyans } \\
(\%)\end{array}$ & $\begin{array}{c}\text { Cronbach Alpha } \\
(\alpha)\end{array}$ \\
\hline & & & 57,339 & ,914 \\
\hline & SB4 & ,791 & & \\
\hline & SB3 & 790 & & \\
\hline & SB2 & 757 & & \\
\hline \multirow[t]{6}{*}{ Bireylerarası Sapma } & SB1 & 691 & 29,778 & ,882 \\
\hline & SB6 & 668 & & \\
\hline & SB7 & 658 & & \\
\hline & SB5 & 652 & & \\
\hline & SO5 & ,757 & & \\
\hline & SO3 & 742 & & \\
\hline \multirow[t]{6}{*}{ Örgüte Yönelik Sapma } & SO1 & 691 & 27,561 &, 855 \\
\hline & $\mathrm{SO} 4$ & 660 & & \\
\hline & SO6 & 644 & & \\
\hline & $\mathrm{SO} 2$ & 627 & & \\
\hline & SO7 &, 598 & & \\
\hline & \multicolumn{4}{|c|}{ KMO:,903; Barlett: 1679,031; df=91; $p=.000<.001$} \\
\hline
\end{tabular}

*Maddeler arası korelasyon değerleri ,45-,74 arasındadır. 
Örgütsel sapma ölçeğinin KMO örneklem yeterliği katsayısı ,903 ve Barlett Küresellik Testi $(p<.001)$ anlamlıdır. SO8 maddesi analizden ,50'nin altında faktör yüküne sahip olduğu için (Maskey, Fei ve Nguyen, 2018, s. 94) çıkartıllmıştır. Bu doğrultuda ölçeğin açıklanan varyansı \%55,594’ten \%57,339'a yükselmiştir. Ölçek yazınla uyumlu olarak iki faktörlü yapıya sahiptir. Ölçeğin ve alt boyutlarının güvenirliği için Cronbach Alfa katsaylları kontrol edildiğinde yüksek düzeyde güvenirliğin söz konusu olduğu tespit edilmiştir.

\section{Bulgular}

Araştırmanın bu bölümünde çoklu doğrusal regresyon analizlerinin bulguları yer almaktadır. Ayrıca çoklu doğrusal bağlantı açısından varyans şişirme çarpanı (VIF) değerleri ve otokorelasyon olup olmadığın kontrolü için de Durbin-Watson değerleri paylaşılmıştır.

Tablo 4. Algzlanan Yönetici Mizahı Boyutlarmm Örgütsel Sapma Davramşı Üžerindeki Etkileri

\begin{tabular}{|c|c|c|c|c|}
\hline Değişkenler & & Bireylerarası Sapma & Örgüte Yönelik Sapma & VIF \\
\hline \multirow{5}{*}{ Sabit } & & $\begin{array}{c}\text { R: ,329; Dz. R²: ,088 } \\
\text { F: 5,406 } 6^{* * *} \text {; Durbin Watson: 1,688 }\end{array}$ & $\begin{array}{c}\text { R: ,326; Dz. R2: ,086 } \\
\text { F: 5,281 }{ }^{* * *} \text {; Durbin Watson: } 1,724\end{array}$ & \multirow{8}{*}{1,75} \\
\hline & $\mathrm{B}$ & 1,227 & 1,313 & \\
\hline & $\mathrm{SH}$ &, 148 &, 135 & \\
\hline & $\mathrm{t}$ & 8,266 & 9,752 & \\
\hline & $\mathrm{p}$ & $.000^{* * *}$ & $.000^{* * *}$ & \\
\hline \multirow{4}{*}{ Alaycı Mizah } & $\beta$ & ,336 & ,305 & \\
\hline & $\mathrm{SH}$ & 053 & 048 & \\
\hline & $\mathrm{t}$ & 4,010 & 3,635 & \\
\hline & $\mathrm{p}$ & $.000^{* * *}$ & $.000^{* * *}$ & \\
\hline \multirow{4}{*}{ Üretici-Sosyal Mizah } & $\beta$ & ,170 & 193 & \multirow{4}{*}{2,336} \\
\hline & $\mathrm{SH}$ & 063 & 057 & \\
\hline & $\mathrm{t}$ & 1,756 & 1,986 & \\
\hline & $\mathrm{p}$ & .080 & $.048^{*}$ & \\
\hline \multirow{4}{*}{ Reddedici Mizah } & $\beta$ &,- 299 &,- 148 & \multirow{4}{*}{2,218} \\
\hline & $\mathrm{SH}$ &, 064 & ,058 & \\
\hline & $\mathrm{t}$ & $-3,169$ & $-1,562$ & \\
\hline & $\mathrm{p}$ & $.002^{* *}$ & .120 & \\
\hline \multirow{4}{*}{ Onaylayıcı Mizah } & $\beta$ &,- 039 &,- 064 & \multirow{4}{*}{1,930} \\
\hline & $\mathrm{SH}$ & 053 & ,048 & \\
\hline & $\mathrm{t}$ &,- 448 &,- 727 & \\
\hline & $\mathrm{p}$ & .655 & .468 & \\
\hline \multirow{4}{*}{ Mizahi Olmayan tarz } & $\beta$ & ,102 &,- 038 & \multirow{4}{*}{1,460} \\
\hline & $\mathrm{SH}$ & 047 & 043 & \\
\hline & $\mathrm{t}$ & 1,331 &,- 498 & \\
\hline & $\mathrm{p}$ & .184 & .619 & \\
\hline
\end{tabular}

VIF değerleri 5'den düşük (Hair, Hult, Ringle ve Sarstedt, 2017, s. 164) olduğu için çoklu doğrusal bağlantı problemi olmadığı görülmektedir. Ayrıca her bir regresyon analizi için Durbin-Watson değerleri kontrol edildiğinde oto korelasyon sorunu bulunmadığı (Field, 2009, s. 220-221) görülmektedir.

Tablo 5. Hipotęlere Illiskin Tablo

\begin{tabular}{|c|c|c|}
\hline Hipotezler & $\begin{array}{c}\text { Bulgular } \\
\text { Bireyleraras1 S. /Örgüte Yönelik S. } \\
\end{array}$ & \\
\hline $\begin{array}{l}\text { H1: Üretici-sosyal mizah tarz1 ÜKİD boyutlarını (bireyleraras1 } \\
\text { sapma ve örgütsel sapma) negatif yönde etkilemektedir. }\end{array}$ & $\beta=, 170 / \beta=, 193^{*}$ & Red \\
\hline $\begin{array}{l}\text { H2: Onaylayıc1 mizah tarzı ÜKİD boyutlarını (bireyleraras1 } \\
\text { sapma ve örgütsel sapma) negatif yönde etkilemektedir. }\end{array}$ & $\beta=-, 039 / \beta=-, 064$ & Red \\
\hline $\begin{array}{l}\text { H3: Alayc1 mizah tarzı, ÜKİD boyutlarını (bireylerarası sapma } \\
\text { ve örgütsel sapma) pozitif yönde etkilemektedir. }\end{array}$ & $\beta=, 336^{* * *} / \beta=, 305^{* * *}$ & Kabul \\
\hline $\begin{array}{l}\text { H4: Reddedici mizah tarzı ÜKID boyutlarını (bireyleraras1 } \\
\text { sapma ve örgütsel sapma) pozitif yönde etkilemektedir. }\end{array}$ & $\beta=-, 299 * * / \beta=-, 148$ & Red \\
\hline $\begin{array}{l}\text { H5: Mizahi olmayan tarz ÜKİD boyutlarını (bireyleraras1 } \\
\text { sapma ve örgütsel sapma) pozitif yönde etkilemektedir. }\end{array}$ & $\beta=, 102 / \beta=-, 038$ & Red \\
\hline
\end{tabular}


Algılanan yönetici mizahı boyutları bireylerarası sapma davranışına ait varyansın \%9'unu açıklamaktadır. Algılanan yönetici mizahı boyutlanından alaycı mizahın bireylerarası sapma davranışını pozitif $(\beta=, 34 ; \mathrm{p}<.001)$, reddedici mizahın ise bireylerarası sapma davranışını negatif $(\beta=-, 30 ; \mathrm{p}<.01)$ yönde etkilediği tespit edilmiştir.

Alg1lanan yönetici mizahı boyutları örgüte yönelik sapma davranışına ait varyansın \%09'unu açıklamaktadır. Algılanan yönetici mizahı boyutlarından alaycı mizahın $(\beta=, 31 ; \mathrm{p}<.001)$ ve üretici-sosyal mizahın $(\beta=, 19 ; \mathrm{p}<.05)$ örgüte yönelik sapma davranışını pozitif olarak yordadığı belirlenmiştir. $\mathrm{Bu}$ bulgular doğrultusunda H1, H2, H4 ve H5’in reddedildiği, H3’ün kabul edildiği görülmektedir.

\section{Tartışma, Sonuç ve Öneriler}

Bu araştırmada algılanan yönetici mizahı boyutlarının ÜKID boyutları üzerindeki etkisini GİET çerçevesinde incelemek amaçlanmıştır. Araştırma sonuçlarına göre, alaycı mizahın hem bireylerarası sapma davranışını hem de örgüte yönelik sapma davranışını orta derecede pozitif olarak etkilediği görülmüştür. $\mathrm{Bu}$ bulgu alaycı mizahın saldırgan mizah olarak da tanımlandığı düşünüldüğünde (Dinç ve Cemaloğlu, 2018) yazınla uyumludur (Comeau, 2016; He ve Li, 2019). GIET açısından değerlendirildiğinde negatif yönetici mizahına uygun nitelikteki alaycı mizah davranışının çalışanlarda olumsuz duygular yaratması sebebiyle onları hem bireylerarası hem de örgüte yönelik sapma davranışlarına yönlendirmesi beklenen bir bulgu olmuştur. Ancak reddedici mizahın bireylerarası sapma davranışını negatif ve üretici-sosyal mizahın örgüte yönelik sapma davranışını pozitif yönde etkilemesini GİET çerçevesinde açıklamak pek mümkün değildir. Çünkü GİET’e göre üretici-sosyal mizahın çalışanlarda pozitif duygular yaratması sebebiyle ÜKID'i engellemesi ve reddedici mizahın da çalışanlarda olumsuz duygular yaratması nedeniyle çalışanları ÜKID'e teşvik etmesi beklenmektedir. Bu noktada ortaya çıkan bu bulguyu GİET’e ek olarak kültürel bağlamın dikkate alınması doğrultusunda yorumlamak daha doğru olacaktır. Örneğin güç mesafesi üzerinden yorumlandığında güç mesafesi yüksek olan örgütlerde çalışanların yöneticilerine daha fazla itaat etme eğiliminde olduğu ve daha otokratik yöneticileri tercih ettikleri (Kemikkıran, 2015) belirtilebilir. Böyle bir ortamda yöneticinin çalışanlarına reddedici mizah ile yaklaşması güç mesafesini korunmasına yardımcı olacaktır. Ancak çalışanın, yöneticisinin mizah anlayışını üretici-sosyal mizah tarzında yorumlaması güç mesafesini azaltıcı bir rol oynayabilir. Bu durumda reddedici mizah yöneticinin ilişkilerinde resmiyete önem verdiğine ve iş disiplinine yönelik bir alg1 yaratması sebebiyle çalışanların işyerinde arkadaşlarına karşı daha tedbirli, mesafeli ve dikkatli davranışlar göstermesini sağlayacaktır. Üretici-sosyal mizah ise çalışanın yönetici samimiyetini ve iyi niyetini yanlış yorumlamasına ve bunu suiistimal ederek iş yerinde örgüte yönelik (işe geç gelme, işten erken ayrılma gibi) sapma davranışlarında bulunmasına sebebiyet verebilecektir. Nitekim Yam ve arkadaşları da (2018) çalışmasında bu araştırmada olduğu gibi espri odaklı olumlu mizah davranışlarının sapma davranışlarını pozitif yönde etkilediğini bulgulamıştır.

Araştırmada onaylayıcı mizah ve mizahı olmayan tarzın ÜKID boyutları üzerinde etkisi bulunamamıştır. Onaylayıcı mizah, üretici-sosyal mizah ile kıyaslandığında üretici-sosyal mizahın daha net bir pozitif mizah tarzı olduğu ifade edilebilir. Mizahi olmayan tarz ile reddedici mizah ve alaycı mizah arasında da negatif mizah açısından benzer bir ilişki söz konusu denilebilir. Buradan hareketle, çalışanların yönetici mizahını yorumlarken, yönetici tarafından daha keskin ve mizah tarzını daha net belli eden eylemlerin sonucu olarak ÜKİD’e yön verdiğini söylemek mümkündür.

Araştırmadan elde edilen bulgular ile yöneticilere çeşitli tavsiyelerde bulunulabilir. Güç mesafesi ve toplulukçu kültürel dinamikler dikkate alındığında, çalışanların yönetici mizah tarzı sonucunda pozitif duygular ile yeni psikolojik kaynaklar inşa etmesi (GİET’in önerdiği gibi) ve bunların örgütün faydasına olacak şekilde yöneticiler tarafindan yönlendirilmesi önem arz etmektedir. Aksi takdirde bu pozitif duyguların yerini suiistimale bırakma riskinin söz konusu olacağı, yeni kaynakların da amaçsızca harcanarak yok olma tehlikesiyle karşı karşıya kalacağı belirtilebilir. Bu noktada yöneticinin kullandığı pozitif mizahın onları motive etmeye yönelik olduğunu ve sinerji yaratmayı amaçladığını çalışanlarına hissettirmesi gerekmektedir. Bu bağlamda, amaçsızca kullanılan mizahın yanlış yönlendirmelere sebebiyet vereceği de ifade edilebilir. Negatif mizah boyutları açısından özellikle alaycı mizah tarzının çalışanlar üzerinde olumsuz sonuçlar yarattığı söylenebilir. Öyle ki, alaycı mizah tarzıyla hareket etmektense reddedici mizah tarzına sahip olmanın daha olumlu sonuçlar ortaya çıkardığı anlaşılmaktadır. Dolayısıyla, yöneticilerin alaycı mizah tarzından uzak durmasının çalısanların işyerinde diğer arkadaşlanına ve örgüte yönelik disiplinsiz davranışlar göstermesinde kısıtlayıcı etki yaratacağı belirtilebilir.

Araştırmanın bazı kısıtları bulunmaktadır. Öncelikle araştırmada algılanan yönetici mizahı ile ÜKID arasındaki ilişki GİET bağlamında incelenmiştir. Bunun yanı sıra araştırma verileri kolayda örneklem 
yöntemiyle elde edilmiş ve araştırma bulguları imalat sektöründe faaliyet gösteren üç firmanın çalışanlarının verdikleri yanıtlar ile sınırlandırılmıştır. Sonraki araştırmalarda iki değişken arasındaki ilişkinin aracı ve düzenleyici değiş̧kenlerin sürece dahil edilmesiyle ve başka örneklemler üzerinde incelenmesi yazına katkı sağlayıcı nitelikte olacaktır.

\section{Etik Beyan}

"Alg̨lanan Yönetici Miz̨abınn Üretkenlik Karşıtı İs Davranışlar Üzerindeki Etkisi” başlıklı çalışmanın yazım sürecinde bilimsel kurallara, etik ve alıntı kurallarına uyulmuş; toplanan veriler üzerinde herhangi bir tahrifat yapılmamış ve bu çalışma herhangi başka bir akademik yayın ortamına değerlendirme için gönderilmemiştir. Araştırmanın gerçekleştirilmesi sürecinde 25.12.2020 tarihinde "Kastamonu Üniversitesi Sosyal ve Beşeri Bilimler Araştırma ve Yayın Etik Kurulu"ndan 4/16 nolu Etik Kurul İzni alınmıştır.

\section{Yazarların Katkısı}

Fikir - B.Ö.; Tasarım - B.Ö.; Denetleme - B.Ö.; Kaynaklar - B.Ö., M.I.; Veri Toplanması ve İşleme - M.I.; Analiz ve Yorum - B.Ö.; Literatür Taraması - B.Ö., M.İ.; Yazı Yazan - B.Ö, M.İ.; Eleştirel İnceleme B.Ö., M.İ.

\section{Kaynakça}

Alan, H. ve Tiryaki Şen, H. (2016). Yöneticilerin kördüğ̈̈mü: Mizah. Psikijatri Hemşireleri Derneği, 7(3), 152-156.

Astedt-Kurki, P. ve Isola, A. (2001). Humour between nurse and patient, and among staff: analysis of nurses' diaries. Journal of Advanced Nursing, 35(3), 452-458.

Avtgis, T. A. ve Taber, K. R. (2006). I laughed so hard my side hurts, or is that an ulcer? The influence of work humor on job stress, job satisfaction, and burnout among print media employees. Communication Research Reports, 23(1), 13-18.

Babad, E. Y. (1974). A multi-method approach to the assessment of humor: A critical look at humor tests. Journal of Personality, 42(4), 618-631.

Barut, Y. ve Onay, M. (2017). Yöneticilerin kullandığı mizah tarzının araştırlması ve mizah kullanımının örgüt üzerindeki negatif ve pozitif etkileri: Türkiye'de örnek bir çalışma. Uluslararası Bilimsel Araștrmalar Dergisis, 416425.

Bennett, R. J. ve Robinson, S. L. (2000). Development of a measure of workplace deviance. Journal of Applied Psychology, 85(3), 349-360.

Berry, C. M., Carpenter, N. C. \& Barratt, C. L. (2012). Do other-reports of counterproductive work behavior provide an incremental contribution over self-reports? A meta-analytic comparison. Journal of Applied Psychology, 97(3), 613-636.

Bilginoğlu, E. ve Yozgat, U. (2018). İşyerinde deneyimlenen eğlencenin pozitif bireysel ve örgütsel çılktlara etkisi. Yasam Becerileri Psikoloji Dergisi, 2(4), 399-413.

Bryman, A. ve Cramer, D. (2005). Quantitative data analysis with SPSS 12 and 13, East Sussex: Routledge.

Brown, T. A. (2006). Confirmatory factor analysis for applied research. NewYork: Guilford Publications.

Büyükyllmaz, O. (2018). Yöneticilerin olumlu ve olumsuz mizah kullanımı ile çalısan tutumları arasındaki ilişki. Anadolu Üniversitesi Sosyal Bilimler Dergisi, 19(2), 125-150.

Campbell, K., Martin, M. M. ve Wanzer, M. B. (2001). Employee perceptions of manager humor orientation, assertiveness, responsiveness, approach/avoidance strategies, and satisfaction. Communication Research Reports, 18(1), 67-74.

Cemaloğlu, N., Recepoğlu E., Şahin, F., Daşçı E. ve Köktürk, O. (2012). Mizah davranışları ölçeğinin geliştirilmesi: Geçerlik ve güvenirlik çalışması. Türk Eğitim Bilimleri Dergisi, 10(4), 693-716.

Churchill, G. ve Peter, P. (1984). Research design effects on the reliability of rating scales: A meta-analysis. Journal of Marketing Research, 21(4), 360-375.

Comeau, C. (2016). The direct and moderating role of bumour styles at work: Organizational citizenship behaviours, counterproductive workplace behaviours, anxiety and depression as organizational outcomes (Yüksek Lisans Tezi). University of Calgary, Kanada.

Cooper, C. D. (2005). Just joking around? Employee humor expression as an ingratiatory behavior. Academy of Management Review, 30(4), 765-776.

Cooper, C. D., Kong, D. T. ve Crossley, C. D. (2018). Leader humor as an interpersonal resource: Integrating three theoretical perspectives. Academy of Management Journal, 61(2), 769-796.

Çakmak, V. ve Baş, Ü. (2016). Mizah tarzları ve problem çözme becerileri: Aksaray büro çalşanları üzerine bir uygulama. Erciyes İletisim Dergisi, 4(4), 115-134.

Çetin, L. ve Altun, S. A. (2018). Okul yönetiminde mizah kullanımına ilişkin yönetici görüşleri. Kocaeli Üniversitesi Eg̈itim Dergisi, 1(2), 85-97. 
Decker, W. H. (1987). Managerial humor and subordinate satisfaction. Social Behavior and Personality: an International Journal, 15(2), 225-232.

Decker, W. H. ve Rotondo, D. M. (1999). Use of humor at work: Predictors and implications. Psychological Reports, 84(3), 961-968.

Diener, E., Thapa, S. ve Tay, L. (2020). Positive emotions at work. Annual Review of Organizational Psychology and Organizational Behavior, 7, 451-477.

Dinç, Ü. G. ve Cemaloğlu N. (2018). İlkokul yöneticilerinin mizah kullanma tarzları ile öğretmenlerin stres yaşama düzeyleri arasındaki ilişkinin bazı değişkenlere göre incelenmesi. Turkish Journal of Educational Studies, 5(2), 1-37.

Evans, T. R. ve Steptoe-Warren G. (2018). Humor style clusters: Exploring managerial humor. International Journal of Business Communication, 55(4), 443-454.

Field, A. (2009). Discovering statistics using spss: introducing statistical method. CA: Sage Publications.

Fredrickson, B. L. (1998). What good are positive emotions? Review of General Psychology, 2(3), 300-319.

Fredrickson, B. L. (2000). Cultivating positive emotions to optimize health and well-being. Prevention \& Treatment, 3 , $1-25$.

Fredrickson, B. L. (2004). The broaden-and-build theory of positive emotions. Philosophical Transactions of the Royal Society of London. Series B: Biological Sciences, 359(1449), 1367-1377.

Fredrickson, B. L. (2013). Positive emotions broaden and build. Advances in Experimental Social Psychology, 47, 1-53.

Fredrickson, B. L., Tugade, M. M., Waugh, C. E. ve Larkin, G. R. (2003). What good are positive emotions in crisis? A prospective study of resilience and emotions following the terrorist attacks on the United States on September 11th, 2001. Journal of Personality and Social Psychology, 84(2), 365-376.

Gruys, M. L. ve Sackett, P. R. (2003). Investigating the dimensionality of counterproductive work behavior. International Journal of Selection and Assessment, 11(1), 30-42.

Hair, J., Hult, T., Ringle, C. ve Sarstedt, M. (2017). A primer on partial least squares structural equation modeling (PLS-SEM). CA: Sage Publications.

He, J. ve Li, D. (2019). What the leader said made me lose control: Leaders' aggressive humor and employees' workplace deviance behaviors. İçinde S. Jang ve Z. Zhu (Edt.), Advances in Social Science, Education and Humanities Research (ss. 249-255). Çin: Atlantis Press.

In'nami, Y. ve Koizumi, R. (2013) Structural equation modeling in educational research: A primer, İçinde M. S. Khine, (Edt.), Applications of structural equation modeling in educational research and practice, Rotterdam: Sense Publishers.

İyigün, N. Ö. ve Çetin, C. (2012). Psikolojik kontratın örgütsel sapma üzerindeki etkisi ve ilaç sektöründe bir araştırma. Öneri Dergisi, 10(37), 15-29.

Kemikkıran, N. (2015). Güç mesafesi yüksekse eşitsizlik mi istenir? Ankara Üniversitesi SBF Dergisi, 70(2), 317-344.

Kiffin-Petersen, S. (2015). Self-Referential emotion regulatory model of work design. İçinde C. E. J. Hartel, W. J. Zerbe vr N. M. Ashkanasy (Edt.), New ways of studying emotions in organizations (ss. 241-269). Bingley: Emerald Publishing Limited.

Lau, V. C., Au, W. T. ve Ho, J. M. (2003). A qualitative and quantitative review of antecedents of counterproductive behavior in organizations. Journal of Business and Psychology, 18(1), 73-99.

Liu, K. W. Y. (2012). Humor styles, self-esteem and subjective happiness. 1: 21-41.

Marcus, B. ve Schuler, H. (2004). Antecedents of counterproductive behavior at work: A general perspective. Journal of Applied Psychology, 89(4), 647-660.

Martin, R. A., Puhlik-Doris, P., Larsen, G., Gray, J. ve Weir, K. (2003). Individual differences in uses of humor and their relation to psychological well-being: Development of the humor styles questionnaire. Journal of Research in Personality, 37(1), 48-75.

Maskey, R., Fei, J. vr Nguyen, H. O. (2018). Use of exploratory factor analysis in maritime research. The Asian Journal of Shipping and Logistics, 34(2), 91-111.

Nayir, K. F. (2016). Developing organizational revenge scale and examining teachers' opinions about organizational revenge. International Online Journal of Educational Sciences, 8(3), 1-15.

Penney, L. M. ve P. E. Spector (2005). "Job stress, incivility, and counterproductive work behavior (CWB): The moderating role of negative affectivity." Journal of Organizational Behavior: The International Journal of Industrial, Occupational and Organizational Psychology and Behavior, 26(7), 777-796.

Robinson, S. L. ve Bennett, R. J. (1995). A typology of deviant workplace behaviors: A multidimensional scaling study. Academy of Management Journal, 38(2), 555-572.

Romero, E. J. ve Cruthirds, K. W. (2006). The use of humor in the workplace. Academy of Management Perspectives, 20(2), 58-69.

Sackett, P. R. (2002). The structure of counterproductive work behaviors: Dimensionality and relationships with facets of job performance. International Journal of Selection And Assessment, 10(1-2), 5-11.

Spanouli, A. ve Hofmans, J. (2020). A resource-based perspective on organizational citizenship and counterproductive work behavior: The role of vitality and core self-evaluations. Applied Psychology: An International Review, 1-28.

Şahin, A. (2016). Illkögretim kurumu yöneticilerinin yönetsel ilişkilerinde kullandıklar mizaha ilişkin görüsler ile mizah iklimi, yöneticilerin mizah tarælar ve çatısma yönetimi stratejileri arasındaki ilişki (Doktora Tezi). Akdeniz Üniversitesi Eğitim Bilimleri Enstitüsü, Antalya. 
Tabachnick, B. G. ve Fidell, L. S. (2013). Using multivariate statistics. New Jersey: Pearson.

Wijewardena, N., Hartel, C. E. ve Samaratunge, R. (2017). Using humor and boosting emotions: An affect-based study of managerial humor, employees' emotions and psychological capital. Human Relations, 70(11), 1316-1341.

Yam, K. C., Christian, M. S., Wei, W., Liao, Z. ve Nai, J. (2018). The mixed blessing of leader sense of humor: Examining costs and benefits. Academy of Management Journal, 61(1), 348-369.

\section{EXTENDED ABSTRACT}

Broaden and Build Theory (BBT) states that positive supervisor humor significantly impacts the emergence of positive emotions in employees (Wiewardena, Hartel, \& Samaratunge, 2017; Cooper, Kong, \& Crossley, 2018). Frederickson (2013), who interpreted the researches conducted on organizations within the scope of BBT, argued that positive emotions increase people's productivity, job performance, physical and mental health. It is predicted that counterproductive work behaviors of employees would be curtailed through the positive emotions engendered by positive supervisor humor. Besides, when it comes to examining negative emotions within BBT, it is emphasized that mental activity is hampered by negative emotions (Fredrickson, 2001). According to BBT, in the researches conducted on organizations; negative emotions are claimed to be a precursor of counterproductive behavior (Kiffin-Petersen, 2015; Diener, Thapa, \& Tay, 2020). Supervisor humor has both positive and negative aspects (Evans \& Steptoe-Warren, 2018). It is predicted that negative supervisor humor will cause negative emotions in employees and lead to counterproductive work behaviors. This is primarily because negative emotions may result in severe damage to both individuals and organizations (Fredericikson, 1998,p. 301).

In their study conducted with a sample of 174 employees and managers, He and Li (2019) found that leaders using aggressive humor have a strong and positive effect on the counterproductive work behaviors of employees. Yam, Christian, Wei, Liao and Nai (2018), in their study with 215 participants from different sectors, examined leader humor in two dimensions as aggressive humor and leaders' sense of humor. They observed that there is no relationship between aggressive humor and counterproductive work behaviors, and leaders' sense of humor has a positive relationship with workplace deviance. Caitlin (2016) investigated the effect of humor used in the organization and its effects on counterproductive work behaviors. Accordingly, it was found that appreciator humor affected interpersonal and organizational deviance negatively, and aggressive humor positively affected interpersonal and organizational deviance. However, self-destructive and producer humor had not been found to have an effect on workplace deviance. In line with these information, research hypotheses have been determined as follows.

- H1: Supervisors' producer humor negatively affects the dimensions of counterproductive work behaviors (interpersonal and organizational deviance).

- H2: Supervisors' appreciator humor negatively affects the dimensions of counterproductive work behaviors (interpersonal and organizational deviance).

- H3: Supervisors' cynical humor positively affects the dimensions of counterproductive work behaviors (interpersonal and organizational deviance).

- H4: Supervisors' rejectionist humor positively affects the dimensions of counterproductive work behaviors (interpersonal and organizational deviance).

- H5: Supervisors' non-humorous style positively affects the dimensions of counterproductive work behaviors (interpersonal and organizational deviance).

The research was conducted with the employees of three firms operating in the "Manufacture of wood and of products of wood and cork, except furniture; manufacture of articles of straw and plaiting materials" sector in Kastamonu. The data were obtained from 228 employees using the convenience sampling method. The questionnaire used in the research is comprised of three parts. In the first part, there is an information form about participants. The second part includes the perceived supervisor humor scale, and the third part comprises the workplace deviance scale. The perceived supervisor humor scale, developed by Cemaloglu et al. (2012), is composed of five dimensions: cynical humor, producer humor, appreciator humor, rejectionist humor, and non-humorous style. The organizational deviance scale developed by Bennett and Robinson (2000) was used in the measurement of counterproductive working behavior. This scale consists of two dimensions. These dimensions are interpersonal and organizational deviances. The validity of these scales was tested through Exploratory Factor Analysis (EFA), and reliability analysis was assessed through the Cronbach's Alpha Coefficient. It is seen that the scales used in the study are divided into dimensions in accordance with the literature. In addition, the reliability level of the scales was found to be quite high. 
Multiple regression analysis was used to test the hypotheses of the research. It is found that perceived supervisor humor explains $9 \%$ of the variance in interpersonal deviance. Moreover, cynical humor, affected interpersonal deviance behavior positively $(\beta=, 34 ; \mathrm{p}<.001)$, while rejectionist humor affected it negatively $(\beta=-, 30 ; \mathrm{p}<.01)$. Perceived supervisor humor dimensions explained $9 \%$ of the variance of organizational deviance behavior. Cynical humor $(\beta=, 31 ; \mathrm{p}<.001)$ and producer humor $(\beta=, 19 ; \mathrm{p}<.05)$ predicted organizational deviance behavior positively. Drawing upon these findings, $\mathrm{H}_{1}, \mathrm{H}_{2}, \mathrm{H}_{4}$ and $\mathrm{H}_{5}$ were rejected, yet $\mathrm{H} 3$ was supported.

Based on the results, it was observed that the cynical humor style affected both interpersonal and organizational deviance behavior positively. When we consider the fact that cynical humor is also identified as aggressive humor (Dinç, \& Cemaloğlu, 2018), this finding is consistent with the previous research (Caitlin, 2016; He and $\mathrm{Li}$, 2019). From the point of BBT, the finding that the cynical humor style directed employees towards both interpersonal and organizational deviance behavior was an expected result. This is because the cynical humor style is evaluated in compliance with negative manager humor, and it results in negative emotions in workers. However, from the BBT's point of view, it seems not feasible to explain why the rejectionist humor negatively affected interpersonal deviance and why the producer humor positively affected organizational deviance. Because, according to BBT, it is expected that 1) producer humor prevents counterproductive work behaviors as it creates positive emotions in employees, 2) rejectionist humor encourages employees to counterproductive work behaviors as it creates negative emotions in employees. At this point, it might be more appropriate to interpret these findings by considering cultural context, in addition to the premises of BBT. 